\title{
O campo do teatro documentário
}

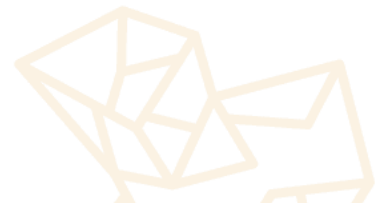

Marcelo Soler ${ }^{1}$

\section{Resumo}

Pautado na pesquisa de doutorado do autor, o artigo pretende apresentar princípios que marcam a especificidade do que se denomina teatro documentário, tendo como principal referência o texto $O$ drama documentário, escrito pelo encenador alemão Erwin Piscator.

Palavras chaves: ; Ficção; Realidade; Teatro Documentário.

Abstract

Based in the doctorate's search of the author, the article intend to introduce principles to ressalt the specifity named Documentary Theatre, with a principal reference to the text "O drama documentário", wrote by german director Erwin Piscator.
\end{abstract}

Keywords: Documentary Theatre ; Fiction; Reality.

\section{Do campo ao sentido, ou de como Piscator semeou o campo}

Na língua portuguesa, a palavra campo remete a um vasto espaço sem uma fronteira visivelmente delimitada. Ao entrar em um campo, caminha-se, localiza-se, posiciona-se e, ao atribuir-lhe sentido, transforma-o em lugar. Da mesma forma, quando se pensa em um campo de conhecimento, pressupõe-se que não se trate de uma área com rígidos contornos, permeada de definições, mas de uma possibilidade de lugar destinado à reflexão.

Assim, a proposição pelo estudo e procura do campo ocupado pelo que se designa como teatro documentário está distante do levantamento de características para uma identificação propulsora de rótulos, ou da criação de uma tipologia sistemática e ordenadora. A busca é direcionada para a localização de princípios que norteariam as produ-

1 Membro fundador da Companhia Teatro Documentário, na qual atua como diretor, dramaturgo e pedagogo do teatro. Graduado em Artes Cênicas pela Escola de Comunicações e Artes da Universidade de São Paulo. Mestre em Artes Cênicas pela mesma instituição, onde, atualmente, desenvolve uma pesquisa de doutorado que se propõe a comparar três processos em teatro documentário de grupos de diferentes países, orientada pelo Prof. Dr. Flávio Desgranges. Em 2010, publicou, pela Editora Hucitec, o livro Teatro documentário: a pedagogia da não ficção, a partir da dissertação de mestrado apresentada no Departamento de Artes Cênicas da Universidade de São Paulo, sob orientação da Profa. Dra. Maria Lucia Pupo. Fazem também parte da Companhia Teatro Documentário: Ananza Macedo, Gustavo Idelbrando, Natalia Lemos e Márcio Rossi. 
ções que, de algum modo, são associadas às práticas em teatro documentário, a fim de encontrar o que fundamenta; logo, o fundamental nelas.

A existência de um termo, associado a uma tradição e a determinadas práticas, afasta a generalização, que é tão perniciosa quanto a criação de definições restritivas e simplificadoras. Ora, de acordo com um pressuposto básico de lógica, se tudo pode ser documentário, nada o é; ou seja, no terreno do relativismo, o termo não teria sentido de existir e uma história repleta de realizações e realizadores seria banalizada no que se refere à pesquisa e às peculiaridades de se documentar em teatro.

Defender a pertinência de um campo específico ao teatro documentário é, sobretudo, respeitar, preservar e agregar o trabalho de artistas que desejaram por motivos diferentes terem sua obra ou parte dela associada ao termo.

Com certeza, Erwin Piscator (1893-1966) é o primeiro nome que vem a mente ao se pensar nas práticas documentais nos palcos; entretanto, atribuir ao encenador alemão a "invenção" do que se chama teatro documentário seria anular experiências anteriores não registradas pela "história oficial," e acreditar que o conceito se constrói pela genialidade de um individuo e não pela sistematização de um sujeito histórico, a partir do legado de outros sujeitos. Estudiosos de diferentes linhas teóricas, como o norte-americano Dawson (1999) e o francês Pavis (1999), creditam aos dramas históricos do século XIX as primeiras manifestações de textos com características documentais, e pontuam que não se deve esquecer da peça A morte de Danton (1835), do dramaturgo alemão Georg Büchner (1813-1837), como um marco, ao se pensar em uma história (ou, porque não, em uma "pré-história"?!) do teatro documentário em termos de dramaturgia. Büchner usou explicitamente certos documentos dentro da construção dramatúrgica de Danton, procedimento esse que será recorrente entre os autores do século XX, filiados ao documentário em teatro.

Ainda assim, na segunda década do século XX, Piscator foi o primeiro a utilizar a palavra documentário em escritos sobre as artes cênicas; ou seja, a abrir caminho para uma conceituação e, com isso, a atrelar determinado modo de se fazer e pensar teatro a um termo, diretamente retirado do universo semântico da linguagem cinematográfica que acabara de nascer.

Nas experimentações do encenador alemão, a imagem audiovisual foi entendida como uma espécie de documento articulado à cena com intuito de comprovar a veracidade histórica dos fatos narrados ou dramatizados pelos atores. Esse uso se apoiava na crescente credibilidade dada às imagens audiovisuais, desde o advento 
do cinema, como registro confiável e comprovável, qualificação que, em nossos dias, ainda persiste "no comércio nebuloso entre arte e verdade" (SONTAG, 2004, p. 180).

Consciente da especificidade da maneira com que fazia teatro, Piscator, em 1929, publica Teatro político, livro no qual reflete sobre sua própria produção teatral, fazendo uma espécie de inventário de opções e teorias.

É nessa obra que, pela primeira vez, utiliza o termo documentário para qualificar uma das peças dirigida por ele. Mais especificamente no capítulo oito, batizado como "O drama documentário", o uso de documentos, em especial de filmes, no espetáculo Apesar de Tudo! (1925) - encenação que trouxe ao palco os fatos relativos à Revolução Alemã de 1918-1919 -, foi descrito e analisado. Neste capítulo, o encenador não se preocupou em teorizar sobre o que seria esse tipo de drama, apenas levou o leitor - por simples associação - a entender que Apesar de tudo! corresponderia a um exemplo de documentário em teatro.

Anterior ao lançamento de Teatro político, a primeira ocorrência em língua inglesa da palavra documentário é atribuída ${ }^{2}$ a uma crítica escrita para o jornal New York Sun, por John Grierson, em 1926, sobre o filme Moana (1926), de Robert Flaherty, muito famosa nos círculos de realizadores de cinema na época e, por consequência, conhecida também por artistas de outras linguagens interessados nas relações entre tecnologia e arte.

Possivelmente, Piscator teve contato direta ou indiretamente com a crítica de Grierson, ou com os ecos dela. Em plena euforia das novas tecnologias da imagem no começo do século XX, nada mais plausível para um artista em diálogo com seu momento histórico do que ter nos primeiros estudos e críticas cinematográficas um referencial teórico para seu trabalho, justificando o mencionado conhecimento e o apreço do diretor em relação à projeção de imagens cinematográficas nas encenações assinadas por ele.

Dawson (1999) cita uma outra suposição para a origem do termo no teatro, levantada pelo pesquisador canadense Alan Douglas Filewod, na pesquisa intitulada The Development and performance of documentary theater in english-speaking Canada. Para Filewod, Brecht teria, em 1926, mesmo ano da crítica de Grieson, se referido às peças de Piscator como épicas e documentárias.

\footnotetext{
2 Em Espelho partido (2006), Da - Rin chega a apresentar a tese do teórico Brian Winston que conseguiu um prospecto do material de divulgação do filme In the land of the headhunters, de 1914, na qual aparecem expressões como "material documentário" e "trabalho documentário". Com isso, pela primeira vez se discutiu a origem do termo no cinema, algo inquestionável até então. (DA-RIN, 2006, 20).
} 
Mesmo quando se considera Brecht como percursor do termo no meio das artes cênicas, novamente se está diante de um nome da história do teatro que nunca escondeu o interesse pela linguagem cinematográfica e a influência dela sobre o seu trabalho como encenador.

Acrescenta-se ainda que a discussão teórica sobre a temática do documentário, já avançada na área do audiovisual, oferece um material que não se refere apenas às peculiaridades do cinema ou do vídeo, mas que também abarca questões sobre o que significa documentar em arte.

\section{Da palavra, ou a semente}

Na teoria presente ao longo da história do cinema, a palavra documentário está associada a um número enorme de filmes que, por sua vez, apresentam métodos, técnicas e estilos com nítidas distinções entre si. Contudo, ao se agruparem em torno de uma mesma denominação, esses filmes se filiam a uma tradição e, obviamente, possuem algo em comum que os une.

Conclui-se que existem inúmeros cinemas documentários que, no entanto, fazem parte do mesmo campo, por afinidades estéticas e processuais:

Por ser "bem desenhado no seu centro de gravidade", o domínio do documentário funciona como catalisador das questões historicamente partilhadas por uma comunidade de praticantes. Questões que, ao longo dos anos, receberam respostas contraditórias, não configurando um campo uniforme e contínuo. Ao contrário, periodicamente novos movimentos e escolas aí se confrontam, dando lugar a sucessivas configurações de documentário (DA-RIN, 2008, p. 19).

Igual raciocínio pode ser desenvolvido no teatro: existem também diversos teatros documentários com diferentes proposições cênicas, mas que abarcam estratégias, opções estéticas e modos de produção com os mesmos alicerces, com a mesma sustentação, com os mesmos princípios:

\footnotetext{
O teatro documentário está ligado à ideia de um teatro como 'espaço de informação alternativa' no mundo submerso por informações no qual nós vivemos, e que pode organizá-las, pensá-las pelo viés do sensível, valendose de toda a prática teatral dos séculos precedentes, das culturas populares ou estrangeiras. Ele apresenta também formas muito diversas, facetas múltiplas (PICON-VALLIN, 2011, p. 1).
}

Independentemente das respostas dadas pelos criadores sobre o que poderia vir a ser um documentário, o termo teve um poder agregador e, ao mesmo tempo, foi responsável por suscitar algumas associações simplificadoras.

Aparte dos princípios que norteariam as produções teatrais ou as cinematográficas qualificadas como tal, a palavra documentário começou a aparecer em constru- 
ções discursivas como uma forma de captar o real tal qual ele se apresenta. Por mais que essa tentativa possa aparecer no projeto de alguns realizadores, ela não pode ser considerada como um fundamento pertinente ao campo do documentário.

De novo os motivos desse fenômeno são encontrados na história do cinema e se referem ao modo como a impressão de autenticidade atribuída à imagem cinematográfica foi aproveitada por aqueles que trabalham com o documentário.

Teóricos como Bill Nichols (2005) chamaram de impressão de autenticidade a propriedade que a imagem cinematográfica tem de estabelecer uma relação de semelhança muita grande com o objeto filmado, por conta de aparatos mecânicos e químicos envolvidos em seu processo de produção. Como consequência, propagou-se a ideia socialmente construída de que as narrativas cinematográficas conseguiriam trazer para as telas de maneira objetiva fatias da realidade.

De modo proposital, esqueceu-se que o ato de filmar refere-se a um recorte do espaço, de determinado angulo, a fim de compor imagens, segundo a necessidade expressiva de quem está por trás da câmera; ou seja, é construção de um sujeito, logo um ato subjetivo.

Os documentários também se apoiaram, sobretudo, na impressão de autenticidade associada à linguagem cinematográfica, no intuito de contar com a crença do público diante daquilo que vê e de assumir um comprometimento com a realidade diferente do que se estabelece com o filme de ficção. ${ }^{3}$ Dessa forma, ao saber que está vendo um filme documentário, o espectador já se prepararia para criar uma interpretação que levasse em conta mais o enfoque da realidade social do que o imaginário do diretor.

Por isso, em alguns momentos históricos, realizadores procuravam usar de modo expressivo o fato de que as imagens captadas, pelo menos em sua maior parte, sofreriam o menos possível qualquer tipo de encenação, entendida, nesse contexto, como arrumação da cena. Queriam se opor a ficção, conjecturando ser o documentário o digno representante da vocação do cinema em trazer supostamente o real para as telas.

Ainda hoje, ao se pensar em um filme documentário, a visão ingênua de que ele objetivaria a fidelidade para com a realidade captada parece se engendrar no imaginário do grande público:

\footnotetext{
A tradição do documentário está profundamente enraizada na capacidade de transmitir uma impressão de autenticidade. E essa é uma impressão forte. [...] Quando acreditamos que o que vemos é testemunho do que o mundo é, isso pode embasar nossa orientação ou ação nele. [...] Assim fazem muitos documentários, quando têm a intenção de persuadir-nos a adotar uma determinada perspectiva ou ponto de vista sobre o mundo (NICHOLS, 2005, p. 20).
}

3 No próximo tópico haverá um esclarecimento sobre o projeto estético do documentário. 
Aproveitar expressivamente a impressão de autenticidade não significa que todos os discursos de natureza documental pretendam ocultar o processo de produção e impor-se com uma pretensa objetividade. Alguns filmes chegam a evidenciar a "voz autoral" e até a problematizar as questões dos limites da representação no documentário, culminando no questionamento da crença dele como instrumento legitimador de verdades, projeto este verificado em uma série de realizadores, principalmente, a partir da década de sessenta do século XX.

Foi justamente em Apesar de tudo! que, pela primeira vez, Piscator investigou o caráter de documento que um fragmento do filme pode ter. Ao projetar as cenas documentais de guerra, o encenador tinha consciência da força e do impacto do audiovisual em comparação aos documentos escritos:

Em Apesar de tudo! O filme foi um documento. [...] As filmagens apresentavam brutalmente todo horror da guerra: ataques com lança-chamas, multidão de seres esfarrapados, cidades incendiadas. Nas massas proletárias aquelas cenas deviam ter influência muito maior que a de cem relatórios. Distribuí o filme por toda a peça, e onde ele não cabia, vali-me de projeções (PISCATOR, 1968, p. 81).

A proposito, outra relação estabelecida na área de teatro com o termo documentário refere-se ao fato de condicioná-lo à dramaturgia e, assim, considerá-lo como marca de gênero. Mesmo com a ampliação do conceito de discurso para algo além dos domínios literários, ainda assim se procura estabelecer com a determinação do gênero uma reflexão "sobre as formas de se estabelecer uma tipologia dos discursos, deduzindo-os de uma teoria geral do fato linguístico e literário" (PAVIS, 199, p. 181). A opção do termo campo, ao invés do termo gênero, leva em conta o projeto estético em torno da encenação como um todo, em oposição a um olhar mais voltado à dramaturgia.

Em proeminentes obras teóricas de diferentes perspectivas de análise, o teatro documentário é considerado um gênero, levando a análises principalmente sobre o texto documental.

No Dicionário de Teatro, de Patrice Pavis (1999), existe um verbete que, além de conceituar o Teatro Documentário, pontua algumas de suas características e o contextualiza dentro da História do Teatro.

O teórico centra sua análise na dramaturgia associada a esse termo. Para ele, há dois principais aspectos que melhor caracterizam o Teatro Documentário como tal: o fato de partir de documentos e fontes, denominadas por ele como autênticas, e a seleção e articulação dessas fontes dentro do texto em torno de uma tese sociopolítica defendida pelo autor (PAVIS, 1999). 
Ainda em uma análise pautada na estrutura textual, Pavis aponta que se verifica principalmente na tradição documentária da literatura dramática o uso da forma de processo jurídico ou interrogatório, priorizando o caráter narrativo do depoimento recoIhido de autos processuais, em detrimento de uma dramatização dos fatos. O dramaturgo funciona, assim, como aquele que seleciona, edita ${ }^{4}$ e articula. Na teorização de Pavis, não se excluem textos que mesclam documento e ficção. (SOLER, 2010)

No livro Documentary Theatre in the United States, Gary Fisher Dawson, um dos teóricos mais dedicados a estudar especificamente o teatro documentário, também o considera um gênero "no qual documentos de fontes primárias são diretamente incorporados no texto dramático e em cada apresentação da peça" (DAWSON, 1999, p. 17). O autor enfatiza a produção dramatúrgica, definindo a peça documental como "aquela pela qual a instituição teatral conferiu o status de teatro documentário com o propósito de aprender, relembrar, interpretar ou responder a um determinado momento histórico" (DAWSON, 1999, p. 17).

Em uma perspectiva para além da literatura dramática, a ideia de campo do teatro documentário parece estar articulada a um território mais abrangente de estudos referente às manifestações teatrais, em especial às das décadas iniciais do século XXI, que combinam "um forte impulso de aproximação com o real à completa rejeição da representação da realidade, ao menos nos moldes realistas" (FERNANDES, 2010, p. 83) e que estão abarcadas pelo termo "Teatros do Real", por sua vez, surgido ainda no final do século XX, com a publicação do livro de Maryvonne Saison, Les Théâtres du réel (1998). Um cuidado deve ser tomado no que concerne ao uso do termo teatro do real: a ênfase na preposição "do" pontua que não se trata de um teatro que se assume como real em seu estado bruto.

A ordem do capital em nossa época chegou talvez a sua mais perigosa estratégia de alienação. A informatização conseguiu acabar com a noção de tempo e espaço ao propor o desaparecimento das distancias via internet. O problema não está na existência da rede, mais na ausência de um movimento crítico claro nos ambientes educacionais sobre como as mudanças no modo de produção interferem no imaginário do cidadão comum.

4 O termo edição relaciona-se a um processo no qual o dramaturgo e/ou o grupo toma o relato de outrem e o corta, inverte ou mistura frases e períodos nele encontrados, visando um tratamento mais interessante da cena. Surge daí uma questão ética indispensável para processos em Teatro Documentário: como editar relatos sem descaracterizar o discurso do primeiro emissor? 
As questões em torno da ficção e da realidade, para alguns caducas, necessitam de nossa consideração. A confusão sobre o que é realidade ou não corrobora para o processo no qual a ficcionalização da vida impede que a força do real nos suscite uma tomada de atitude também real. O próprio dado documental, mesmo não sendo o real em natureza bruta, perde também sua força expressiva.

Um dado documental do porte de uma imagem audiovisual da fome na África, exaustivamente reproduzida nos meios de comunicação de massa e na internet, vai perdendo seu poder persuasivo na banalizada ratificação de comentários como: "isso realmente acontece!". A imagem torna-se mais uma atração que nos suscita o horror, assim como uma cena de novela pode alcançar.

É exatamente em um momento onde a realidade se ficcionaliza que o campo do teatro documentário reaparece com maior ênfase. E, a partir dessa constatação, observa-se a necessidade de mapear seu espaço e discutir o porquê dessa necessidade.

\section{No que se configura o campo}

$\mathrm{Na}$ procura de apontar os princípios que permitem vislumbrar o campo do que se chama teatro documentário, novamente se recorre à teoria do cinema, mas especificamente às palavras de Fernão Ramos (2008, p.7), quando o autor afirma que "a definição de documentário se sustenta sobre duas pernas, estilo e intenção, que estão em estreita interação ao serem lançadas para a fruição do espectador, que as percebe como próprias de um tipo narrativo que possui determinações particulares".

Do mesmo modo, no teatro é na relação entre a intencionalidade em documentar, o consequente trabalho com dados não ficcionais e a percepção por parte do espectador da natureza documentária do discurso que é possível existir o que chamamos de documentário.

Logo, faz-se necessário discutir um pouco cada uma dessas três instâncias, ratificando ainda mais que não se trata de características classificatórias, mas de princípios.

Sobre a intencionalidade de documentar, autores como Nichols (2005) e Da-Rin (2008) constatam a importância da presença de um projeto estético diferenciado ao do filme de ficção, diretamente relacionado a essa intenção, para a consolidação do cinema documentário, pensamento esse que pode ser trabalhado nos domínios das artes cênicas.

A partir do aparecimento do termo documentário na crítica de Grierson, um olhar mais atento recaiu sobre outros filmes que apresentavam, assim como Moana, a intenção de registrar fatos, pessoas e/ou lugares, a partir de uma experimentação poética, culminando no aparecimento da voz narrativa e, sobretudo, de uma retórica 
própria. Um retorno à produção de anos anteriores, permitiu que se convencionasse como marco da produção documental a estreia do filme Nanook, o esquimó (Naook of the north, de Robert Flaherty, Canadá/Estados Unidos, 1922), uma obra de refinada narrativa sobre a vida dos inuits, povo denominado, de modo geral, como esquimó. Os próprios nativos apresentavam diante das câmeras seus costumes, a partir de instruções de Flahert. Procedimento esse que já refuta a ideia de que o documentário cinematográfico não pode se pautar por cenas "fabricadas" pelo diretor.

Diferentemente dos filmes de viagem que tinham uma intencionalidade científica ou prezavam por saciar a curiosidade de lugares distantes e culturas exóticas a um certo público, Nanook apresentava características formais diferentes. Críticos da época, como afirma Da-Rin (2008), "revelaram de forma eloquente" o impacto causado pelo filme:

A novidade radical deste filme estava na abertura de um novo campo de criação situado entre os filmes de viagem e ficções, sem se identificar propriamente com nenhum dos dois modelos. Em outras palavras, era o fruto do encontro do travelogue com o modo de representação ficcional que alguns anos antes se instituíra (DA-RIN, 2008, p, 46).

A abordagem em nada imparcial dada à realidade, presente nesse primeiro documentário e que persistirá ao longo da história, estava pautada pelo ponto de vista do documentarista, resultando em um discurso que como tal possui um emissor com interesses artísticos comunicacionais determinados.

Do mesmo modo, nos domínios das artes cênicas, Piscator em Apesar de tudo!, ainda que o termo documentário já existisse, ${ }^{5}$ já intencionava o documentar e não o confundia como o mero registro da realidade.

$O$ ato de documentar, já com Piscator, adquire uma conotação investigativa, pois pressupõe que o documentarista tenha um olhar, ${ }^{6}$ compreendido aqui como ponto de vista, tentando perceber na realidade dados que em si são metáforas para entendê-la de maneira mais ampla.

Para o encenador, era necessário revisitar no palco a Revolução Alemã de 19181919 - que culminou com a derrubada do Kaiser e o estabelecimento de uma república democrática, mas que levou ao assassinato de Rosa Luxemburgo e Karl Liebknecht, fundadores da Liga Espartaquista, de tendência próxima ao comunismo liber-

5 Vale ratificar que se o vocábulo documentário apareceu em determinado contexto é porque a materialização daquilo que o caracteriza já pré-existia. Ao nomear algo se dá (cons-)ciência para que esse algo efetivamente possa ser objeto de uma percepção mais acurada, objeto de estudo.

6 No contexto, o termo olhar se associa ao posicionamento do sujeito sobre algo, a visão que extrapola os domínios do próprio olho. 
tário - para dizer que, apesar da espantosa derrota, "a revolução social progredirá" (PISCATOR, 1968, p. 79).

O desejo de retomar determinado momento histórico sob um ponto de vista, presente em Apesar de tudo!, liga o ato de documentar diretamente à necessidade da construção do passado; logo, da atribuição de significados à experiência vivida, advindo da vontade em criar uma narrativa que memorialize o que se documentou.

Do mesmo modo, quase como consequência da necessidade de se documentar, é a pesquisa e procura de fontes para criação da narrativa documental. Apela-se, então, para documentos de toda ordem, sem que se considere obrigatório explorá-los para que o documentário possa existir.

O próprio termo documentário sempre esteve atrelado à palavra documento pela raiz etimológica comum. Talvez, por isso seja perceptível o paralelo entre os vários redimensionamentos do que se considera teatro documentário e as mudanças pelas quais a noção de documento passou.

A partir do século XIX, a palavra documento vai aparecer nos discursos legais (judiciário e policial) associada à ideia de prova, comprovação da verdade. Da mesma forma, na época, apenas o registro escrito se validaria como tal, conquistando também o status de testemunho objetivo e imparcial.

Apenas na década de sessenta do século XX, conforme afirma o historiador francês Jacques Le Goff (1992), houve uma ruptura na ideia de documento como registro objetivo da realidade, promovida em muito pelos escritos do filósofo francês Michel Foucault (1926 - 1984). Le Goff afirma que, acompanhado ao questionamento, começaram progressivamente a ser entendidos como documentos outros materiais objetos, relatos orais gravados em fita, vídeos, fotos - além dos papéis escritos.

Longe da imparcialidade que muitos the atribuem, o documento é encarado contemporaneamente como o produto de um olhar sobre determinado fato, havendo um esforço para decifrar as informações contidas nele e manifestadas no suporte material do registro, no processo de elaboração, na realidade em que ele foi produzido e, sobretudo, nos interesses de sua construção:

Foucault não chama a atenção apenas para o fato de que também a memória é uma forma de relato, modo de elaborar a experiência. Seu objetivo é demonstrar que o fundamento da história é a intencionalidade social. [...] É o fator intencionalidade que faz com que o documento seja percebido como monumento - resultado da tentativa de se impor ao futuro determinada imagem da sociedade. Assim, não existe um documento-verdade (SANTOS, 2000, p. 48). 
A mudança de perspectiva em relação ao que se considera documento influenciou diretamente a teorização sobre o conceito de documentário, motivando o questionamento da ideia de que ele se configura na apresentação da verdade nas telas ou nos palcos.

Parte-se do pressuposto que o discurso documental construído é uma interpretação do que se deu e, portanto, a enunciação, como tal, se articula conforme os interesses, os valores e a intencionalidade dos enunciadores. Temas como discos voadores, assombrações ou entidades folclóricas, podem ser alvo de documentação que defenda sua existência, sem com isso caracterizar o discurso resultante como ficcional.

Porém, mesmo teóricos ainda hoje atuantes, como Dawson (1999), conferem aos documentos o poder de trazer uma credibilidade ao que está sendo contado em cena, como se o acontecimento em si pudesse ser trazido aos palcos e não uma versão deles:

Uma peça documental é uma forma persuasiva de teatro que se aproxima ao máximo possível de um acontecimento com confiança exclusiva em documentação de materiais históricos precisos. Mais diretamente, o teatro documentário é um gênero em que documentos de fontes primárias são diretamente incorporados no texto dramático e em cada apresentação da peça (DAWSON, 1999, p. 17)

A definição dada pelo autor sobre o que caracteriza uma peça de teatro documentário não consegue abarcar encenações documentais que optam por inserir documentos sem uma validade histórica consagrada.

Essa perspectiva se distancia, por exemplo, da presença de documentados em cena relatando suas experiências, como encontramos nos projetos do coletivo suíço-alemão Rimini Protokoll. O trabalho do Rimini aponta para uma ideia interessante: o documentado funcionando como documento vivo dentro da encenação.

Tanto o uso do documento tradicional como a presença do documentado em cena são consequências imediatas da intencionalidade em documentar, no sentido de estabelecer um comprometimento outro com a realidade em comparação àquelas obras que não pretendem ser documentários. Com a abordagem em e para a cena de documentos, objetiva-se construir asserções sobre a realidade, em uma exploração diferente da obtida quando se trabalha com produtos assumidamente ficcionais.

Porém, de nada adianta a intencionalidade em documentar e o trabalho com e sobre os documentos se o espectador não tem uma elaboração a partir de uma percepção documental. Em última análise, é o olhar do espectador que transforma o que está sendo apresentado em documentário. 
No pacto estabelecido entre artistas (enunciadores) e público (fruidores) diante de um documentário (enunciação), pressupõe-se que os fruidores levem em conta o enfoque dado à realidade social que, de algum modo, permeia a construção discursiva, mais do que o imaginário dos criadores.

Para haver o pacto, o público, previamente ou durante a encenação, deve ter a percepção de que está diante de um documentário. A fruição de um relato sobre um assassinato é diferente quando sabemos que aquelas palavras foram as mesmas utilizadas pelo assassino real em seu julgamento.

Como foi discutido até aqui, mesmo que carregado de associações inapropriadas a conceitos como o de verdade, objetividade, realidade, o termo documentário, muitas vezes conhecido dos espectadores por meio do contato prévio deles com as produções audiovisuais, passa a funcionar como uma espécie de elemento chave que detona a experiência documental.

A indexação - entendida como o ato de pôr um índice, indicar o tipo de experiência que o autor/autores deseja $(\mathrm{m})$ proporcionar aos espectadores - é explicitada por mecanismos sociais em discursos de natureza diversa da teatral, como peças publicitárias (cartazes, folders, flyers) utilizadas na divulgação da encenação e nas informações contidas em reportagens, críticas ou mesmo sinopses. Esses textos lidos e fruídos de antemão alimentam o imaginário da plateia, que já nesse instante começa a entrar em processo de significação.

A presença e a exploração da indexação levam a considerações acerca do fenômeno teatral dentro de um mundo altamente informatizado, cujas pessoas dialogam frequentemente com inúmeros meios de comunicação de massa e se utilizam deles para optar pelo que irão "se entreter". Todas as informações adquiridas pelo que foi lido, visto e/ou ouvido criam uma espectativa e começam a nutrir o imaginário do espectador. Alguém que inadvertidamente entra na sala de espetáculo estabelecerá uma relação totalmente diferente com o objeto artístico daquela experimentada pelo espectador já preparado por esses discursos extraespetaculares:

Ao recebermos a narrativa como documentária, estamos supondo que assistimos a uma narrativa que estabelece asserções, postulados, sobre o mundo, dentro de um contexto completamente distinto daquele no qual interpretamos os enunciados de uma narrativa ficcional (RAMOS, 2008, p. 27).

Independente da indexação, o contato do espectador com um documentário cênico, em princípio, pode ser árduo. A abordagem ficcional presente inclusive nos produtos de não ficção trabalhados pelos meios de comunicação de massa criou um 
formato hegemônico. A necessidade da parábola e de elementos característicos da narrativa ficcional, muitas vezes, leva à resistência daquele que pressupõe assistir algo que reproduzirá um modelo recorrente, interferindo, assim, na fruição da obra.

A propósito da questão, o trabalho de Flávio Desgranges, em torno da recepção teatral, ratifica a coautoria atribuída ao espectador que dialoga com o objeto ou ato artístico na tentativa de travar um diálogo, recorrendo para isso ao seu patrimônio pessoal, em um movimento que demanda trabalho, de certo modo, uma atuação frente ao que é fruído, pois "ser espectador requer esforço, não há saída, um esforço criativo" (DESGRANGES, 2003, p. 30).

Numa proposta de teatro documentário, questões específicas são apresentadas para o espectador. O acervo da memória social, por exemplo, trazido à baila pelos documentos de ordem sonora, imagética ou escrita é matéria do gesto artístico. Inquietações surgem: o que esse dado tem a nos dizer? Como ele se articula com os outros signos que compõem o discurso? As referências sobre o fato, pessoa/grupo social e/ou época documentados são solicitadas em busca de uma decodificação. Não há como escapar, os dados documentais fazem com que o contato direto com uma versão sobre os acontecimentos históricos requeira do espectador seu posicionamento sobre os mesmos.

$\mathrm{Na}$ perspectiva do fazer documental, ocorre uma relação diferente entre os documentaristas, o alvo da documentação e os espectadores que acaba por suscitar também questões de ordem ética. Se o documentário se propõe a investigar a realidade e faz, a partir disso, asserções sobre o mundo histórico, o comprometimento com o que é dito passa a ser outro. Incorre, portanto, novas inquietações partilhadas entre realizadores e espectadores: como falar dos outros ou de situações históricas sem cair em estereótipos ou na banalização? O que fazer com os documentados depois da realização do documentário? Se o documentário não é a verdade e sempre se estará lidando com a interpretação dos fatos, quando o documentarista está enganando os espectadores e quando ele está apenas exercitando sua "licença poética"?

As inquietações levantadas são urgentes em um mundo onde o encontro com o outro cada vez mais é suscitado pela possibilidade de usufruto, ou seja, motivado pelo que aquele sujeito/objeto tem a me oferecer. As máximas do "no que vou lucrar com isso?" e do "consumo e descarto" estão indiretamente presentes. 
A proposição de um processo em teatro documentário, portanto, oferece aos envolvidos (documentaristas, documentados, espectadores) a oportunidade de questionamento ético sobre questões urgentes em dias que o "show do eu" impera sobre a "consciência do nós".

\section{Referências Bibliográficas}

BERNARDET, J. C. O que é cinema. São Paulo: Nova Cultura, 1985.

DAWSON, Gary Fisher. Documentary theatre in United States. Westport: Greenwood Press, 1999.

DA-RIN, Silvio. Espelho partido - tradição e transformação do documentário. São Paulo: Azougue Editora, 2008.

DEBORD, Guy. A sociedade do espetáculo. Rio de Janeiro: Contraponto, 2007.

DESGRANGES, Flávio. A pedagogia do espectador. São Paulo: Hucitec, 2003.

FRANCO, Marília. A natureza pedagógica das linguagens audiovisuais. In: Coletânea Lições com Cinema. São Paulo: FDE, 1993.

NICHOLS, B. Introdução ao documentário. Campinas: Papirus Editora, 2005.

PAVIS, P. Dicionário de teatro. São Paulo: Perspectiva, 1999.

RAMOS, Fernão P. Mas afinal... o que é mesmo documentário? São Paulo: Editora Senac, 2008.

PICON-VALLIN, Béatrice. Os novos desafios da imagem e do som para o ator. Folhetim, Rio de Janeiro, Teatro do Pequeno Gesto, n. 21, p. 6-23, jan-jun. 2005.

Teatro híbrido, estilhaçado e múltiplo: um enfoque pedagógico. Sala Preta, v. 11, n. 1 , p. 193-211, 2011. DOI: http://dx.doi.org/10.11606/issn.2238-3867.v11i1p193-211

PISCATOR, Erwin. Teatro político. Rio de Janeiro, Editora Civilização Brasileira, 1968.

ROUBINE, Jean-Jacques. A linguagem da encenação teatral, 1880 - 1980. [trad. Yan Michalski] Rio de Janeiro, Jorge Zahar, 1998

ROSENFELD, A. Prismas do Teatro. São Paulo, Editora Perspectiva, 1993.

RYNGAERT, Jean-Pierre. Introdução à análise do teatro. [trad. MÔNICA Stahel] São Paulo, Martins Fontes, 1996

SONTAG, S. Sobre a Fotografia. São Paulo, Companhia das Letras, 2004.

WEISS, Peter. 14 unkte zum dokumentarischen Theater. Dramen, vol. 2, Suhrkamp, Frankfurt, 1968. 